\title{
A Study on Linear Generator Characteristics in Free Piston Engine
}

\author{
Ly Vinh Dat ${ }^{1, ~ *, ~ N g u y e n ~ T h a i ~ H o c ~}{ }^{2}$ \\ ${ }^{1}$ Faculty of Vehicle and Energy Engineering, Ho Chi Minh City University of Technology and Education, Ho Chi Minh City, Viet Nam \\ ${ }^{2}$ Faculty of Automotive Engineering, Ho Chi Minh Industry and Trade College, Ho Chi Minh City, Viet Nam
}

Email address:

datlv@hcmute.edu.vn (L. V. Dat)

${ }^{*}$ Corresponding author

\section{To cite this article:}

Ly Vinh Dat, Nguyen Thai Hoc. A Study on Linear Generator Characteristics in Free Piston Engine. International Journal of Transportation Engineering and Technology. Special Issue: Transportation Engineering Technology and Education. Vol. 7, No. 3, 2021 , pp. 78-84. doi: 10.11648/j.ijtet.20210703.13

Received: August 21, 2021; Accepted: August 25, 2021; Published: August 31, 2021

\begin{abstract}
The linear generator (LG) is integrated into a system that called the free piston linear generator (FPLG). In recent year, free piston engine that is studied by many researchers, has some advantages. Therefore, the application of the line generator in free piston for converting the chemical energy to electrical energy that can be used for plug-in hybrids to extend the range of operations as an alternative energy converter. Therefore, the optimizing of linear generator performance be able to significantly reduce the vehicle's fuel consumption. The parameters in permanent magnet linear electric machine (PMLEM) are designed by Maxwell software and the optimal parameters is carried out via the flux density. To achieve this goal, a linear generator in free piston engine with a flat structure and quasi-Halbach array flux structure was proposed. The simulation of linear generator is performed based on the speed ranges in the New European Driving Cycle (NEDC) for a mid-size car. In the study, a linear electrical machine (LEM) is designed by Maxwell software with translator that has various diameters. The results show that the suitable parameters for stator and rotor about $7.7 \mathrm{~mm}$ and $14 \mathrm{~mm}$, respectively. Because the flux density for this design's stator and rotor yoke avoids saturation state and generates the highest electrical output compared to the other states. Besides, the paper also examined the power output at different frequencies from $15 \mathrm{~Hz}$ to $50 \mathrm{~Hz}$, corresponds to a velocity amplitude of $3.6 \mathrm{~m} / \mathrm{s}$ to 12 $\mathrm{m} / \mathrm{s}$. The simulation result shows that the frequencies from $15 \mathrm{~Hz}$ to $30 \mathrm{~Hz}$ with $4.8 \mathrm{~m} / \mathrm{s}$ to $7.2 \mathrm{~m} / \mathrm{s}(1200 \mathrm{rpm}$ to $2100 \mathrm{rpm})$, respectively meets engine speed operation ranges in hybrid vehicle and these frequencies produce the power output that increases considerably about $7.5 \mathrm{~kW}$ at $30 \mathrm{~Hz}$.
\end{abstract}

Keywords: Free-piston Linear Generator, Free Piston Engine, Maxwell, Permanent Magnet Generators, NEDC Driving Cycle

\section{Introduction}

Nowadays, many researchers always concentrate on the drawbacks of conventional vehicle such as fossil fuel crisis and global environment problems, their studies focus on the converting the conventional fuel to alternative fuels that has low emissions, high engine performance and efficiency. Hybrid electric vehicle (HEV) that meets about the above problems, it seems to be the best solution for this crisis in this period, whereas the electric vehicle need considerably improvement about battery life and cost. These advances in battery technology will be solved in future but hybrid vehicle combine between the conventional engine and electric motor still the best solution on present transportation. Free piston engine with linear generator has advantages in improving the charge method in hybrid vehicle. Hence, the free piston linear alternator (FPLA) which is regarded as one of the devices to overcome the battery drawbacks about moving distance [1]. The FPLA, which combines the free piston internal combustion engine (FPICE) and the linear alternator (LA), is integrated the advantages of the two parts. This machine has only one moving part and suffers less from the friction force in operating. The piston motion is not constrained, therefore some advance technologies as variable compression ratio 
(VCR), homogeneous charge compression ignition (HCCI) and alternative fuel that are applied in free piston engine easily. Consequently, free piston engine can improve engine performance, efficiency and emission. As another main part of FPLA, the LA is be directly utilized the linear piston force without any need of the additional mechanical components that are necessary in a rotary configuration. FPLA is thus an effectively integrated energy conversion device.

Many institutions such as the German Aerospace Centre (DLR), Toyota Central R \& D Labs Inc. (Toyota), and the Nanjing University of Science and Technology (NUST), have carried out many studies on the single-cylinder FPLGs. Kock et al. at DLR has developed a two-stroke single-cylinder FPLG with the gas spring functioning as a rebounding device [2-5]. The results showed that it could produce an electric power output about $10 \mathrm{~kW}$ at $21 \mathrm{~Hz}$. The output power could be further improved up to $25 \mathrm{~kW}$ by increasing the motion frequency up to $50 \mathrm{~Hz}$.

The dual-piston type FPLG is a common configuration that has been widely studied by many institutions such as the Royal Institute of Technology (KTH), West Virginia University (WVU), Shanghai Jiao Tong University (SJTU), Newcastle University and the Beijing Institute of Technology (BIT) [6-7]. Hansson et al. at KTH developed a dual-piston FPLG prototype. The rated power of the generator was produced about $29 \mathrm{~kW}$. The system mean efficiency is $23 \%$. Their work mainly focused on the optimization design of the linear electric machine specifically that is used in FPLG [8]. Shoukry et al. at WVU established a dual-piston two-stroke prototype, which could produce a peak output electric power of $316 \mathrm{~W}$ with a frequency of $23.1 \mathrm{~Hz}$ [9-11]. Xiao et al. at SJTU have also studied the dual-piston FPLG. They also developed a prototype and the motion characteristics of the prototype were thoroughly investigated [12].

There are also a few studies on the opposed-piston FPLGs. Van Blarigan et al. at Sandia National Laboratory (SNL) developed an opposed-piston prototype. Their purpose proposed to a FPLG design about $30 \mathrm{~kW}$ as the fuel cell for a hybrid electric vehicle (HEV) [1, 13]. The synchronous control of the opposed-piston FPLG is relatively more difficult than the single-piston and dual-piston types.

The studies of different connective structures in PMLEM can generally be classified according to geometrical structure which includes the two main types: flat type and tubular type. The main advantage of the tubular type is the net radial force between the motor and stator is zero, and there is no terminal winding. However, the magnetic rings and tubular stator are difficult to produce, furthermore there are limited external dimensions, the cross-sectional areas of the coil are limited by the diameter of the magnetic rings in the PMLEM. Although structure of a flat-type LEM is relatively simple, it has some disadvantages such as the terminal coil. Nowadays, the both types are investigated by researchers in the world. A study conducted by $\mathrm{Li}$ et al. Of Shanghai Jiao Tong University performed a simulation study for both flat and tubular linear alternating generators [14]. The study used the finite element models to simulate and compare the maximum voltage, current density, specific power, and efficiency of two AC generators. The work concluded that the flat type linear generator has high efficiency, specific power, output voltage and current compared with the tube type. Therefore, the flat type linear generator is the most suitable choice for FPLE in hybrid electric vehicle.

The magnetic flux structures in the Permanent Magnet Linear Electric Machine (PMLEM) were proposed by Junnan Wang, Nick J Baker [15], gave some main types of PMLEMs under study for applications (Free-Piston Linear Generator, FPLG). The study shown that the Transverse Flux Permanent Magnet Linear Electric Machine (TFPMLEM) has the large flux density, however, the power ratio is small due to the large flux leakage and its complex structure makes high production cost. Hence, it needs to be researched and improved in future. For the Flux Switching Permanent Magnet Linear Electric Machine (FSPMLEM) type, the study found that it is not competitive to apply due to the leakage up to $65 \%$ compared with TFPMLEM even it is improved about tooth structure. Furthermore, the horizontal flux machine has some advantages such as overall performance, power, efficiency and small displacement mass. Compared with SMPMLEM, both undergo a large moving mass which will result in the low frequency of motion and slowly dynamic response. Therefore, an SMPMLEM has the smallest moving mass and high reliability due to their simple motor structure and robustness and characteristic with high force density and efficiency. SMPMLEM quasi-Halbach array shows the best average performance in bearing capacity, moving mass according to simulation studies, so it can improve the overall performance of SMPMLEM [15], which is selected. for this article.

\section{Free- Piston Linear Generator System}

From the previous studies, the authors find that the single-cylinder FPLG, which is stable performance control easily that comparing to the dual-piston and opposed-piston engine types. Hence, the single-piston FPLG with gas spring recovery device is considered as a promising design. However, the long-term stable operation of the single-cylinder FPLG remains a difficult problem. Besides the lack of effective control strategies, improper system design can also lead to unstable operation. To solve the above difficulties, the German Aerospace Center (DLR) has researched the design of the flat-type linear generator coupled with the opposed-piston engine technology on the free piston [4]. Thanks to the integration of gas springs at the rear of the combustion piston, the free-piston engine can further reduce the length. Because of high efficiency and reaching many advantages for dual-piston design, DLR is developing the FPLG system with the central combustion chamber (Figure 1). In this paper, the arrangement is also the basis for the design of a linear generator on a free-piston engine. Figure 2 describes a free piston linear generator that is developed by DLR in vehicle. 


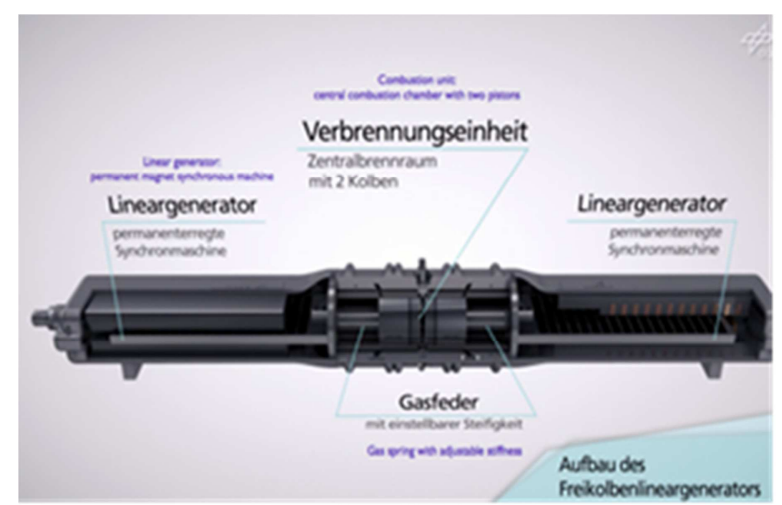

Figure 1. The DLR linear generator structure.

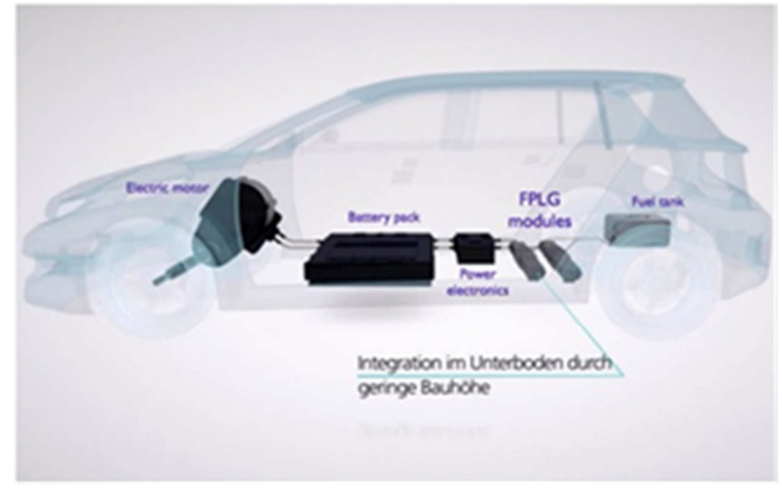

Figure 2. The linear generator layout on DLR vehicle.

\section{Design of the Linear Electrical Machine (LEM)}

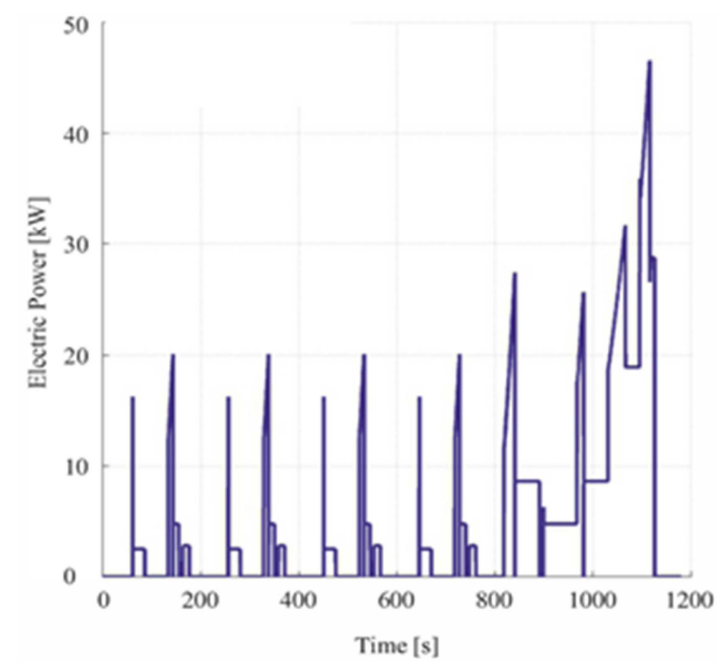

Figure 3. Illustration of the electrical power required in the New European Driving Cycle [5].

The FPLG power outputs for design are based on the speed configuration of the New European Driving Cycle (NEDC) for a mid-size automobile [5]. This vehicle was chosen because it represents a large number of cars which are used in Europe. Taking into consideration the acceleration processes resulting from the New European Driving Cycle, the electrical power outputs required as illustrated in Figure 3, which were determined through simulation results.

The energy demand simulation chart provides the required power output of the vehicle engine for NEDC. This is the reference value for the design of FPLG concepts. This cycle is divided into two phases. During the first 780 seconds, an urban driving cycle is repeated four times. As can be seen in Figure 3, the highest power demand here is about $20 \mathrm{~kW}$. In the second phase, the car runs an additional urban loop with a maximum speed of $120 \mathrm{~km} / \mathrm{h}$. For acceleration, the maximum power does not exceed $50 \mathrm{~kW}$. This analysis shows that the range extender generator on PHEV hybrid vehicles needs only $50 \mathrm{~kW}$ or less, depending on the size of the electrical storage capacity, to pass NEDC. Especially with larger batteries, the output power of the FPLG can be designed to be significantly smaller under $50 \mathrm{~kW}$.

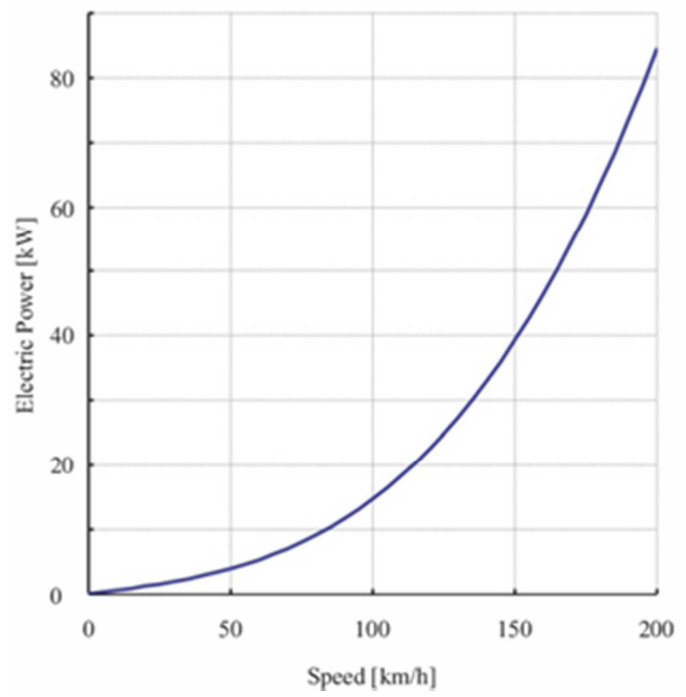

Figure 4. Required power for constant maximum speed.

In Figure 4, the power required to drive at a constant speed show that an FPLG system with $20 \mathrm{~kW}$ is sufficient for a continuous speed of about $120 \mathrm{~km} / \mathrm{h}$. With a NEDC maximum power required about $50 \mathrm{~kW}$, the car is considered to reach a continuous speed about $165 \mathrm{~km} / \mathrm{h}$. An FPLG system with 100 $\mathrm{kW}$ will provide speeds up to $200 \mathrm{~km} / \mathrm{h}$ or reserve sufficient acceleration at lower speeds without using battery power.

From the analysis results above in Figure 3 and Figure 4. According to the New European Driving Cycle (NEDC), the $30 \mathrm{~kW}$ FPLG system is sufficient to achieve a continuous speed of about $135 \mathrm{~km} / \mathrm{h}$ [11], which is assumed for design of linear generator in this paper. With the FPLG system structure, it is expected that there will be a pair of linear generator module on only one opposing free-piston engine as shown in Figure 1. There will be two FPLG systems as shown in Figure 2 on a car. Each of generator module will have an actual power of about $7.5 \mathrm{~kW}$, so choosing the desired power to calculate the generator parameters of $10 \mathrm{~kW}$.

Desired power $P_{i n}=10000 \mathrm{~kW}$, because $\cos \varphi \approx 1$ (generator circuit with assumed load is circuit $R L$ with very small $L)$ so $S_{i n}=10000 \mathrm{VA}$; Phase inductive voltage $E_{p h}=120 \sqrt{3}=40 \sqrt{3} \mathrm{~V}$. To illustrate in detail for the option to 
set the input parameters for a linear generator, the paper proposed the design of the $30 \mathrm{~kW} \mathrm{FPLG}$ with stroke $S=120$ $\mathrm{mm}$ as an example based on the New European Driving Cycle (NEDC) [5].

Part of the generator is used in 2D space modeling with FEMM 4.2 software. In order to avoid excessive saturation of the stationary (stator) and the moving part (rotor) their permissible flux density has been less than $1.8 \mathrm{~T}$ for the stator wall (due to the stator material Steel_1010) and to rotor is less than $1.2 \mathrm{~T}$ (because the rotor material is Steel 1008). The LEM structure is designed in Figure 5, Figure 6 and Figure 7 with design parameters are shown in Table 1.

Table 1. Linear Electrical Machine Parameters.

\begin{tabular}{ll}
\hline Stator core & \\
\hline Length $L_{s}$ & $396.002 \mathrm{~mm}$ \\
Width $W_{s}$ & $80 \mathrm{~mm}$ \\
Slot opening $b_{s}$ & $22 \mathrm{~mm}$ \\
Tooth width $b_{t}$ & $10.154 \mathrm{~mm}$ \\
Spring magnet thickness $h_{s}$ & $8 \mathrm{~mm}$ \\
Stator yoke $Y_{s}$ & $7.3 \mathrm{~mm}$ \\
Permissible flux stator yoke $B_{y}^{s}$ & $1.8 \mathrm{~T}$ \\
Mean diameter of the windings $D_{w}$ & $1.628 \mathrm{~mm}$ \\
Tooth high $\tau_{t}$ & $33 \mathrm{~mm}$ \\
Translator core & \\
Pole pitch $\tau_{p}$ & $23 \mathrm{~mm}$ \\
Rotor yoke $Y_{r}$ & \\
Permissible flux rotor yoke $B_{y}^{r}$ & $1.2 \mathrm{~T}$ \\
Winding & \\
Number of phases m & 3 \\
No. of poles p & 12 \\
Number of slots/ phase/ pole q & $1 / 3$ \\
Turn number/ coil $N_{c}$ & 50 \\
Air gap flux density, $B_{g}$ & $0.8 \mathrm{~T}$ \\
Airgap, g & $2 \mathrm{~mm}$ \\
Slot filling factor $K_{c u}$ & 0.6 \\
Permanent Magnet & \\
Magnet length $\tau_{m}$ & $20.7 \mathrm{~mm}$ \\
Magnet thickness $h_{m}$ & $8 \mathrm{~mm}$ \\
Residual magnetic flux density $B_{r}$ & $1.17 \mathrm{~mm}$ \\
Coercive magnetic field intensity $H_{c}$ & $868000 \mathrm{~A} / \mathrm{m}$ \\
\hline
\end{tabular}

Table 2. Parameter to stator and translator.

\begin{tabular}{llll}
\hline Stator & $7.3 \mathrm{~mm}$ & $7.3 \mathrm{~mm}$ & $7.3 \mathrm{~mm}$ \\
Translator & $7.7 \mathrm{~mm}$ & $14 \mathrm{~mm}$ & $18 \mathrm{~mm}$ \\
$B_{y}^{s}$ & $1.72 \mathrm{~T}$ & $1.72 \mathrm{~T}$ & $1.72 \mathrm{~T}$ \\
$B_{y}^{r}$ & $2.02 \mathrm{~T}$ & $1.19 \mathrm{~T}$ & $0.89 \mathrm{~T}$ \\
\hline
\end{tabular}

In the study, the permissible flux densities for stator yoke are 1.8 $\mathrm{T}$ and rotor yoke is $1.2 \mathrm{~T}$. Therefore, the suitable design is performed with various translator diameters at $7.7 \mathrm{~mm}, 14$ $\mathrm{mm}$ and $18 \mathrm{~mm}$ respectively. Whereas stator diameter is fixed at $7.3 \mathrm{~mm}$ for all states due to space design limit. The results are shown in Table 2. The suitable translator diameter is 14 $\mathrm{mm}$, due to the flux density in permissible ranges. While the flux density of rotor yoke is $2.02 \mathrm{~T}$ for $7.7 \mathrm{~mm}$. This is larger than permissible value $(1.8 \mathrm{~T})$, hence the stator is saturated at $7.7 \mathrm{~mm}$ state. Otherwise, the flux densities for stator and translator have values at $1.72 \mathrm{~T}$ and $0.89 \mathrm{~T}$, respectively. These flux densities have small value compared to the permissible values, it leads to generate the small electrical output. Hence, the stator wall size of $7.7 \mathrm{~mm}$ and the rotor wall size of $14 \mathrm{~mm}$ is the best suitable flux density that has values in the permissible region, this avoids saturation in the stator wall and rotor with $B_{y}^{s}=1.72 T<1.8 T$ and $B_{y}^{r}=1.19 T<1.2 T$

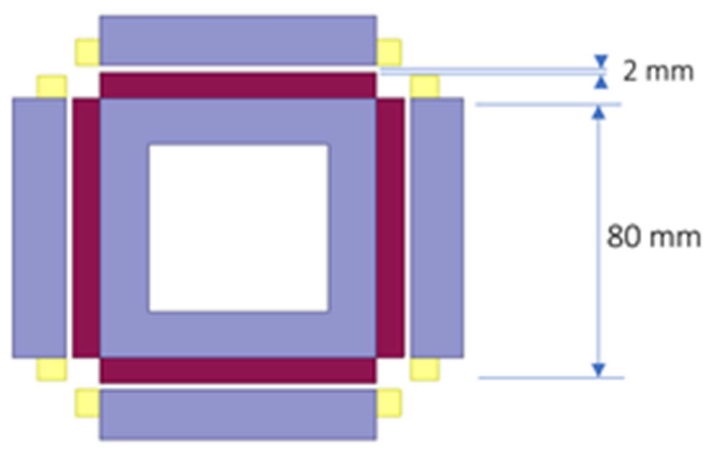

Figure 5. Flat projection of linear generator.

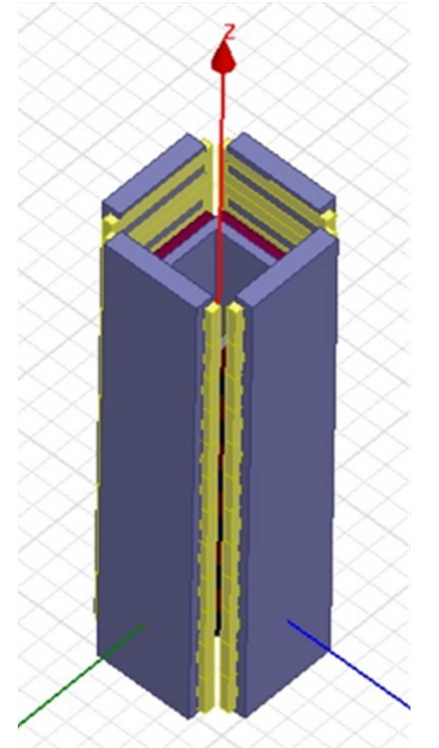

Figure 6. Linear Electrical Machine Model.

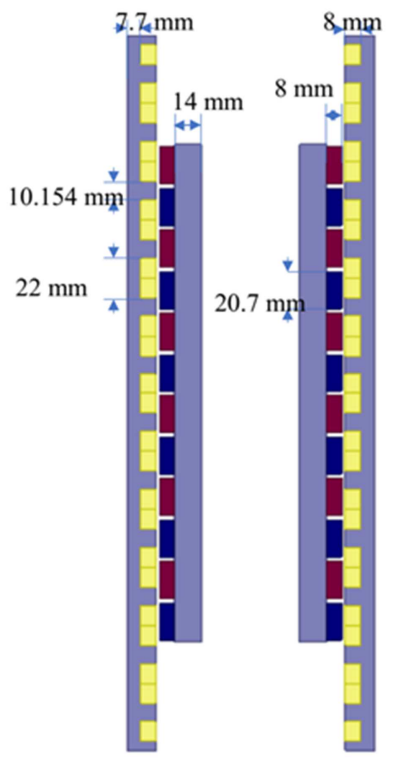

Figure 7. The vertical section of the linear generator. 


\section{Simulation Results}

The magnetic flux density $\mathrm{B}$ (Tesla), electromagnetic density $\mathrm{J}\left(\mathrm{A} / \mathrm{m}^{2}\right)$, magnetic field strength $\mathrm{H}(\mathrm{A} / \mathrm{m})$ at $15 \mathrm{~Hz}$ have described in a 3D model for stator (stationary part) and translator (moving part) as Figure 8 and Figure 9.

At $15 \mathrm{~Hz}$, the generator stator flux density has a maximum value of $B_{y \max }^{S}=1.7603 T<1.8 T$ and the minimum value of $B_{y \min }^{S}=0.00227986 T$. With such flux density value, the generator stator is not over saturated with flux.

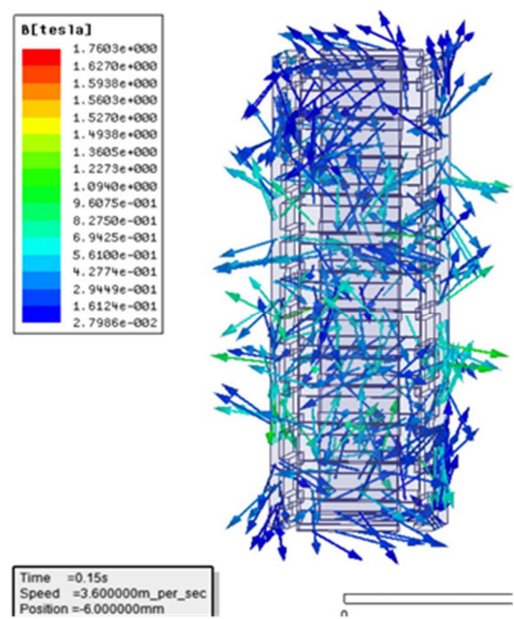

Figure 8. The flux density B for stationary part (stator) of generator at $15 \mathrm{~Hz}$.

At $15 \mathrm{~Hz}$, the generator rotor flux density has a maximum value of $B_{y \max }^{S}=1.983 T<1.2 T \mathrm{~B}$, and a minimum value of $B_{y \min }^{S}=0.01499 T$. With such flux density value, the generator rotor is not over saturated with flux.

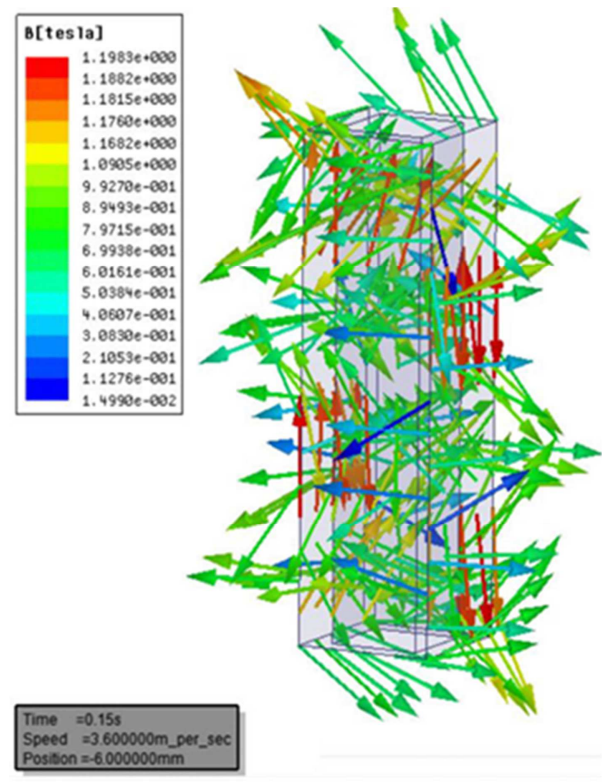

Figure 9. Plot of flux density B for translator of generator at $15 \mathrm{~Hz}$.

Linear generator modeling was performed mainly in Ansys Maxwell software and used FEMM and Matlab Simulink software for supporting. Simulation results show that the generator is not excessively saturated with flux at the core of the static part (stator) and the dynamic part (rotor). The simulation results about current, voltage at $15 \mathrm{~Hz}$ with $3.6 \mathrm{~m} / \mathrm{s}$, respectively are described in Figure 10, Figure 11 and Figure 12. The result show that the maximum current is $I_{p h}=2.3 \mathrm{~A}$, while the maximum phase voltage magnitude is $E_{p h}=26 \mathrm{~V}$ and the maximum polarity voltage is $V_{\text {out }}=14.7 \mathrm{~V}$ at $15 \mathrm{~Hz}$.

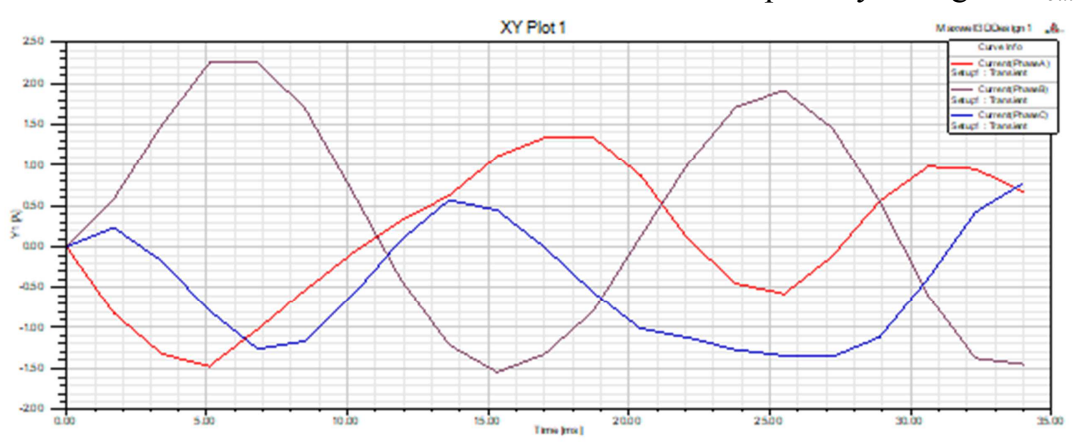

Figure 10. 3-phase current for linear generator at $15 \mathrm{~Hz}$.

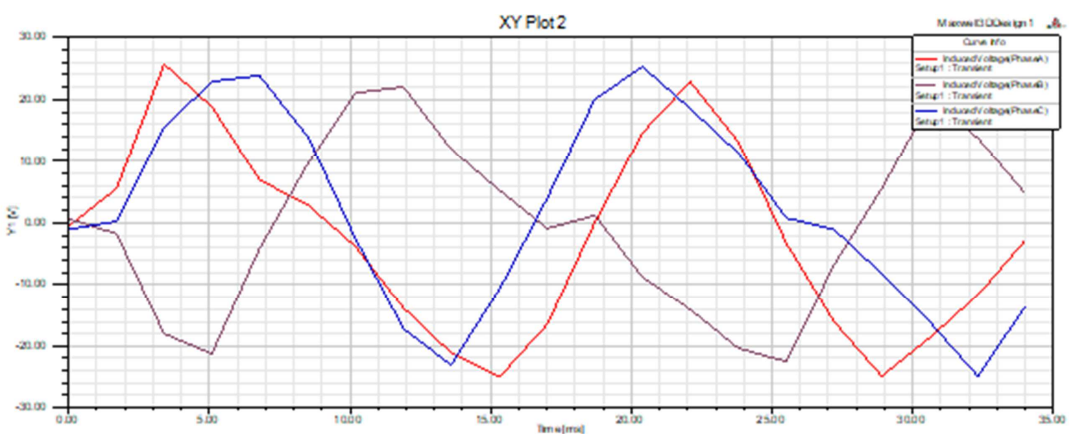

Figure 11. 3-phase voltage for linear generator at $15 \mathrm{~Hz}$. 


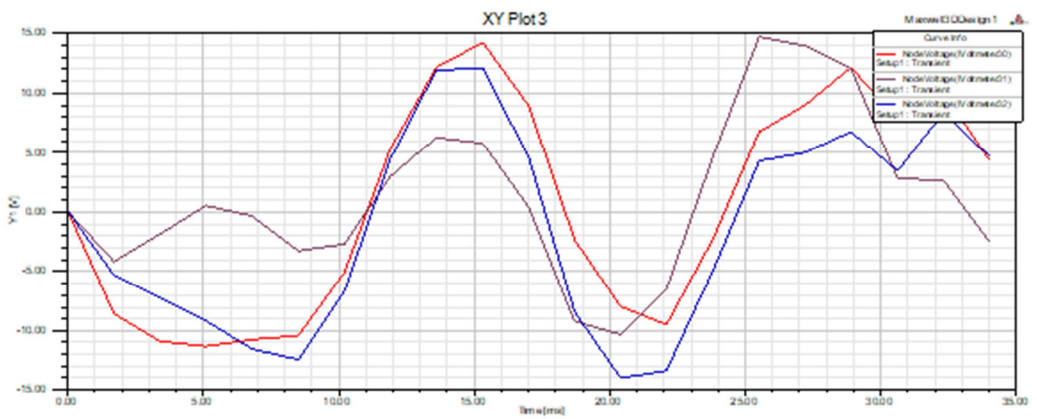

Figure 12. Voltage for linear generator load at $15 \mathrm{~Hz}$.

The other frequencies are practiced similar to these above processes. The power of the linear generator at the various frequencies from $15 \mathrm{~Hz}$ to $50 \mathrm{~Hz}$, corresponds to a velocity amplitude of $3.6 \mathrm{~m} / \mathrm{s}$ to $12 \mathrm{~m} / \mathrm{s}$, shown in Table 3 .

Table 3. Pin input power and generator Pout output power at frequencies from $15 \mathrm{~Hz}$ to $50 \mathrm{~Hz}$.

\begin{tabular}{lll}
\hline Frequencies f $(\mathbf{H z})$ & Power Input $\mathbf{P}_{\text {in }}(\mathbf{W})$ & Power Output $\mathbf{P}_{\text {out }}(\mathbf{W})$ \\
\hline 15 & 179.4 & 452.5 \\
20 & 452.5 & 227 \\
25 & 607.1 & 311.4 \\
30 & 754 & 375.4 \\
35 & 802.3 & 407 \\
40 & 835.6 & 418.7 \\
45 & 872.3 & 435.6 \\
50 & 897.6 & 448.8 \\
\hline
\end{tabular}

The magnitude of the output power and input power from $15 \mathrm{~Hz}$ to $50 \mathrm{~Hz}$ of the linear generator is shown in Figure 13.

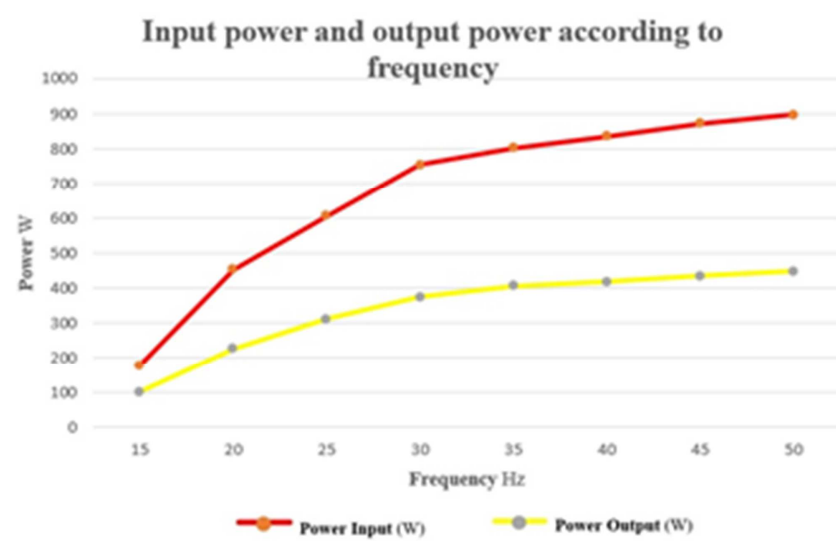

Figure 13. Generator input and output power chart from $15 \mathrm{~Hz}$ to $50 \mathrm{~Hz}$.

The input and output power are proportional to the frequency and speed of the linear generator. When the motor frequency is $30 \mathrm{~Hz}$, the speed is $7.2 \mathrm{~m} / \mathrm{s}$, the input power and output power increase slightly.

The generator efficiency varies from $50 \%$ to $55 \%$, as the frequency increases the efficiency of the generator also increases. However, the value of $P_{\text {in }}$ and $P_{\text {out }}$ have a bigger difference.

When the engine has speed amplitude $V_{r m}=7.2 \mathrm{~m} / \mathrm{s}(f=30 \mathrm{~Hz})$ or more, the generator produces $P_{\text {out }} \approx 7.5 \mathrm{~kW}$ output power or more in accordance with the requirements for use in hybrid vehicles. When the linear generator reaches velocity amplitude $V_{r m}=7.2 \mathrm{~m} / \mathrm{s}(f=30 \mathrm{~Hz})$ the power of the generator starts to increase slightly, so increasing the motor speed is too high. The free-piston engine of FPLG system with speed range from $4.8 \mathrm{~m} / \mathrm{s}$ to $7.2 \mathrm{~m} / \mathrm{s}$ or $1200 \mathrm{rpm}$ to $2100 \mathrm{rpm}$ (or frequencies from $15 \mathrm{~Hz}$ to $30 \mathrm{~Hz}$ ) is suitable for linear generators that used on electric hybrid vehicle.

\section{Conclusions}

In the FPLG, the LEM design is one of the crucial techniques for achieving high power density and stable performance. LEM permanent magnets are the most suitable solution for FPLG. The use of a linear generator with a Halbach PM array is an effective way to reduce the mass of motion and improve the efficiency of the dynamic response. The flat type construction is more suitable for space limited applications. Motion magnet LEMs are preferred for high power FPLGs because of their high reliability compared to motion coils. Both TFPMLEM and FSPMLEM can achieve high power density but have low power factor and complex structure, and the combination of both PMLEM may be a promising option that needs further research.

The mechanical parameters for the linear generator simulation are based on those of the German Space Agency-DLR free piston engine with a piston stroke of 120 $\mathrm{mm}$ and reaching $50 \mathrm{~Hz}$. The feasibility of the linear generator in the paper is shown by the numerical simulation results on Ansys Maxwell software from $15 \mathrm{~Hz}$ to $50 \mathrm{~Hz}$ with a velocity range from $3.6 \mathrm{~m} / \mathrm{s}$ to $12 \mathrm{~m} / \mathrm{s}(1200 \mathrm{rpm}$ to $2100 \mathrm{rpm})$. Simulation results show that the generator is not excessively saturated with flux at the core of the static part (stator) and the dynamic part (rotor). For free-piston engine frequencies from $15 \mathrm{~Hz}$ to $50 \mathrm{~Hz}$, the amperage of linear generators ranges from $2.3 \mathrm{~A}$ to $3.4 \mathrm{~A}$; Phase voltage ranges from $26 \mathrm{~V}$ to $88 \mathrm{~V}$; Pole voltage ranges from $14.7 \mathrm{~V}$ to $40 \mathrm{~V}$; Input power ranges from 179.4 W to $897.6 \mathrm{~W}$; Output power ranges from $101.4 \mathrm{~W}$ to $448.8 \mathrm{~W}$; and the efficiency ranges from $50 \%$ to $56.5 \%$.

The input and output power are proportional to the frequency and speed of the linear generator. When the motor frequency is $30 \mathrm{~Hz}$ at the speed is $7.2 \mathrm{~m} / \mathrm{s}$, the input power and output power increase slightly.

\section{Acknowledgements}

The authors would like to acknowledge Ho Chi Minh City 
University of Technology and Education' help which has sponsored this research.

\section{References}

[1] P. Van Blarigan, "Free-Piston Engine," In Proceedings of the 2009 DOE Vehicle Technologies Program Annual Merit Review, Arlington, VA, USA; pp. 1-17, 2009.

[2] F. Rinderknecht and F. A. Kock, "High Efficient Energy Converter for a Hybrid Vehicle Concept-Gas Spring Focused," In Proceedings of the Symposium EVER12, Monte Carlo, Monaco, 22-24 March 2012.

[3] F. Kock, J. Haag, H. E. Friedrich, "The Free Piston Linear Generator-Development of an Innovative, Compact, Highly Efficient Range-Extender Module," SAE Tech. Pap, 2013.

[4] C. Ferrari, H. E. Friedrich, "Development of a Free-Piston Linear Generator for use in an Extended-Range Electric Vehicle," In Proceedings of the EVS26 International Battery, Hybrid and Fuel Cell Electric Vehicle Symposium, Los Angeles, CA, USA, 6-9 May, 2012.

[5] S. Schneider, F. Rinderknecht and H. E. Friedrich, "Design of Future Concepts and Variants of The Free Piston Linear Generator," In Proceedings of the 2014 Ninth International Conference on Ecological Vehicles and Renewable Energies (EVER), Monte Carlo, Monaco, pp. 1-8, 25-27 March 2014.

[6] P. Zheng, A. Chen, P. Thelin, W. M. Arshad and C. Sadarangani, "Research on a Tubular Longitudinal Flux PM Linear Generator Used for Free-Piston Energy Converter," IEEE Trans. Magn. Vol 43, pp. 447-449, 2007.

[7] J. Hansson, M. Leksell, "Performance of a Series Hybrid Electric Vehicle with a Free-Piston Energy Converter," In Proceedings of the Vehicle Power and Propulsion Conference, Windsor, UK, pp. 1-6,.6-8 September 2006.

[8] J. Hansson, M. Leksell, F. Carlsson and C. Sadarangani, "Operational Strategies for a Free Piston Energy Converter". In Proceedings of the Fifth International Symposium on Linear Drives for Industry Applications, Kobe-Awaji, Japan, 25-28 September 2005.

[9] P. Khayyer, P. Famouri, "Application of Two Fuel Cells in Hybrid Electric Vehicles,” SAE Tech. Pap. 2008.

[10] E. F. Shoukry, "Numerical Simulation for Parametric Study of a Two-Stroke Compression Ignition Direct Injection Linear Engine," West Virginia University: Morgantown, WV, USA, 2003.
[11] E. Shoukry, S. Taylor, N. Clark and P. Famouri, "Numerical Simulation for Parametric Study of a Two-Stroke Direct Injection Linear Engine," SAE Tech. Pap. 2002.

[12] J. Xiao, Q. Li, Z. Huang, "Motion Characteristic of a Free Piston Linear Engine,” Appl. Energy, Vol 87, pp. 1288-1294, 2010.

[13] T. Johnson, "Free-Piston Engine," Sandia National Laboratories: Albuquerque, NM, USA, 2012.

[14] Q. F. Li, J. Xiao, Z. Huang, "Flat-type Permanent Magnet Linear alternator: a suitable device for a free piston linear alternator," J. Zhejiang Univ.-Sci. A (Appl. Phys. Eng.) Vol 10, pp. 345-352, doi: 10.1631/jzus.a0820224, 2009.

[15] J. Wang, N. J. Baker, "Comparison of Flux Switching and Modulated Pole Linear Machines for use with a Free Piston," In Proceedings of the IEEE International Electric Machines \& Drives Conference (IEMDC), Coeur d'Alene, ID, USA, pp. 642-648, 10-13 May 2015.

\section{Biography}

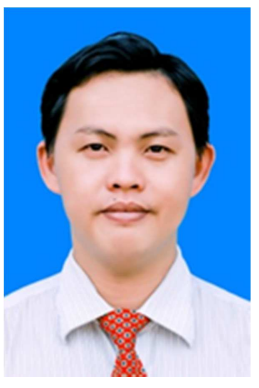

Ly Vinh Dat (Viet Nam). He hold associate Professor in 2017, and graduated $\mathrm{PhD}$ of Mechanical and Electrical Engineering in 2013, National Taipei University of Technology, Taipei, Taiwan. Research interests: Efficiency improvement in SI and CI engines, Intake and exhaust systems, Electro-magnetic valve train, improving of efficiency, fuel consumption and emission in internal combustion engines, etc. Work experiences: has taught as a lecturer at Faculty of Vehicle and Energy Engineering, University of Technology and Education Ho Chi Minh City, Vietnam, since 2003.

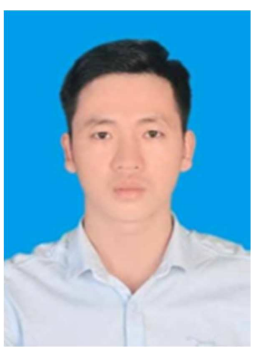

Nguyen Thai Hoc - was born in Vietnam. He received his master degree in Vehicle Engineering from Ho Chi Minh City University of Technical Education (HCMUTE) in 2021. He is a lecturer at faculty of Automotive Engineering at Ho Chi Minh Industry and Trade College. His research interests include engine advance technologies, engine management systems, hybrid and electric vehicle. 